Revista Iberoamericana. Vol. LXV, Núms. 188-189, Julio-Diciembre 1999; 483-504

\title{
NEGRISMO: \\ HIBRIDEZ CULTURAL, AUTORIDAD Y LA CUESTIÓN DE LA NACIÓN
}

\author{
POR \\ JEROME BRANCHE \\ University of Pittsburgh
}

To free the slave is discovered to be tolerable only in so far as it freed his master.

W.E.B. Du Bois.

I

El llamado movimiento negrista o afroantillano del período entre las dos guerras mundiales, ${ }^{1}$ se ofrece en su aspecto literario y extraliterario como fascinante tema para el estudio de los procesos interculturales que marcan el colonialismo, y el encuentro entre pueblos antes aislados que éste efectúa. ${ }^{2}$ Tantas décadas después de pasar de moda, el negrismo retiene su importancia por ser una de las bases sobre las que se entablan los debates y diálogos de la identidad cultural en el Caribe hispanohablante en el siglo XX. A partir de estos debates, se reconoce el mestizaje ético-cultural afroespañol de una manera que atenúa el maniqueísmo del postulado civilización/barbarie que definía el discurso identitario decimonónico y colonial en América Latina.

El reconocimiento del sincretismo afroespañol en el discurso oficial de la identidad cultural nacional en el Caribe y América Latina, se nos presenta como un hito histórico cuya importancia simbólica no es de subestimar. Sobretodo si tomamos en cuenta la importancia del movimiento de la négritude, la descolonización de posguerra, el triunfo de la revolución cubana, la institucionalización de los derechos civiles en Estados Unidos, y más recientemente el desmantelamiento del Apartheid, Se trata del movimiento de huída vertiginosa de lo

${ }^{1}$ El marco temporal del negrismo es poco fijo. Antologías claves de la poesía negrista, como la de Ramón Guirao, y el libro de Luis Palés Matos, representan colecciones a posteriori de un movimiento que había tenido vida a través de poemas esparcidos por varios periódicos y revistas en años previos. La antología de Emilio Ballagas de 1946 (Mapa de), así como el Pregón de Marimorena de la uruguaya Virginia Brindis de Salas, indican el hecho de que aunque se registra en ese momento como movimiento continental, en las antillas la moda ya había pasado su punto culminante. Al mismo tiempo piezas como las de José Manuel Poveda ("El grito abuelo") de 1915 (González-Pérez 31), y de Felipe Pichardo Moya ("La comparsa") de 1916 (Mansour y González 75), son manifestaciones tempranas de lo que luego se convirtió en boga apasionada.

${ }^{2}$ Aquí uso el término "intercultural" para señalar el flujo y reflujo de influencias culturales en el marco político y social de la colonia esclavista. Este uso reconoce el centrismo hegemónico de la cultura dominante sin ver éste como un poderío unidireccional. 
negroafricano como marcador socio-étnico negativo (legado de la esclavitud y la sociedad de castas) a sonoros planteamientos que celebran el mestizaje racial y cultural. Así las hondas preocupaciones sociales que provocaran las imputaciones de "impureza de sangre" bajo el régimen legal colonial, ${ }^{3}$ y que vuelven a ser expresadas por los ideólogos nacionalistas bajo el positivismo blanquizante del siglo diecinueve, vienen a repostularse en la actualidad bajo el tropicalismo mestizo.

El objetivo del presente ensayo es analizar el negrismo (celebración temporaria de los símbolos de una etnicidad oprimida), no como una inversión desinhibida de valores por parte de sus protagonistas, según mantiene cierta óptica crítica, sino más bien como un reposicionamiento de las coordenadas de la hegemonía con respecto al debate de la etnicidad y la identidad nacional. El ensayo parte de la premisa de que tanto el devenir histórico, como la misma agencia de los sectores sociales dominados, hacen necesarias parecidas mudanzas de coyuntura en aras del mantenimiento del equilibrio entre las fuerzas sociales. Plantea que la celebración del negrismo, lejos de constituir la democracia racial, participa del proceso de la creación de un nuevo consensus o "definición" de la realidad, que es dirigida en última instancia, a mantener el status quo. Como nos señala Stuart Hall, evocando a Marx, tal redefinición es una tarea ideológica a la que responde la clase dominante en cada época. El crítico nos recuerda también que, "el sistema dominante debe [...] hacerse y rehacerse continuamente, para así 'refrenar' aquellos significados, prácticas, y valores que le son oposicionales". ${ }^{4}$ Sostengo además, que el negrismo, ya sea a nivel textual, antológico, o hermenéutico, delata aquella voluntad de mando que caracteriza el discurso hegemónico.

De la paradoja de un movimiento que se define por el sintagma "afro" - llámese afroantillanismo, afrocubanismo, negrismo, mulatismo, o lo que sea- pero cuya autoría carece en gran medida de escritores negros, surge el tema de quizás mayor controversia e importancia crítica en el movimiento, es decir su plurietnicidad autorial de facto. De esta paradoja deviene todo un aparato crítico y hermenéutico neoliberal dirigido no sólo a la explicación de la presencia mayoritaria de autores blancos en un movimiento "negro", sino a establecer la trascendencia de éstos en él. Esto converge, por ejemplo, en lo que dio en llamarse una "doctrina crítica", la cual gobierna (o busca gobernar) la lectura de los textos negristas, vista por ejemplo, en una de las antologías postreras del movimiento (Albornoz, Sensemayá: La poesía negra 9).

Dicha "doctrina" explicaría la plurietnicidad autorial del negrismo como la expresión de una competencia cultural transracial por parte de sus autores no-negros, que los capacita para representar al sujeto negro "desde dentro". Propone, además, que esta capacidad de representación transracial es producto de un proceso histórico de síntesis cultural armoniosa,

\footnotetext{
${ }^{3}$ Los certificados de "gracias al sacar", estaban dirigidos a exculpar la imputada impureza de sangre. Mantenían la premisa de la supremacía blanca, permitiendo a la vez la movilidad social entre los subordinados étnicos, es decir, a pesar de su "mala sangre". Los tomos de Konetzke reproducen numerosos decretos reales que ordenaban la exclusión de negros, mulatos, indios, etc. de puestos eclesiásticos, de ciertos oficios, de instituciones educativas, etc.

4 "The dominant system must [...] continually make and remake itself so as to 'contain' those meanings, practices and values which are oppositional to it" (Stuart Hall, "Culture, the Media and the "Ideological Effect" 332. Ésta, y las traducciones de cita que a continuación se hacen, son responsabilidad del autor).
} 
de relaciones raciales amistosas y de una historia esclavista que fue paternalista y benigna. Arropado en esta teoría, viene el mito de la democracia racial, con el corolario de que al contrario de los viejos modelos de segregación estadounidense o sudafricano, en América Latina rigen y han regido la convivencia y el humanismo en el campo de las relaciones raciales. ${ }^{5}$

El consensus acerca de este modelo de relaciones raciales latinoamericanas y de la interracial, es compartido y expresado en mayor o menor medida por varios críticos y antólogos tales como Rosa Valdés-Cruz, Hortensia Ruiz del Vizo, Armando GonzálezPérez, Mónica Mansour (Poesía negra), así como Aurora de Albornoz y Rodríguez Luis en el mencionado Sensemayá. Aparece en la introducción a las antologías, o bien, a lo largo de sus comentarios sobre la poesía negrista (véanse por ejemplo, Valdé-Cruz 67, Ruiz del Vizo 9-17, González-Pérez 10, Mansour 11-12, y Albornoz y Rodríguez Luis 28). Esta explicación de la plurietnicidad autorial tiene una de sus más tempranas expresiones, como se puede averiguar, en la crítica de Emilio Ballagas, quien fuera, junto con su compatriota Nicolás Guillén y el puertorriqueño Luis Palés Matos, uno de los principales negristas según establece la evaluación canónica.

Ballagas fue el editor de unas de las primeras antologías de poesía negrista, el Cuaderno de poesía negra (1934), colección suya, la Antología de la poesía negra americana (1935) y el Mapa de la poesía negra americana (1946). Además de los comentarios editoriales que acompañaban sus antologías de los años 1935 y 1946, y un artículo de 1937 bajo el título de "Poesía negra liberada", Ballagas también publicó una disertación doctoral en 1946 sobre la "Situación de la poesía afroamericana".

En su introducción a la Antología y al Mapa, Ballagas propone como rótulo a esta poesía de temática negra, no el de "poesía negra", sino el de "poesía mulata". Busca reflejar así - a cambio de lo que sucede con el caso de la versificación contemporánea afroestadunidense, o de una poética africana- la heterogeneidad étnica de esta poesía en el Caribe y en América del Sur. Al explicar la presencia de autores blancos en la Antología y la supuesta habilidad de éstos para "traducir con fidelidad el espíritu afro-cubano" (19), el editor se apoya en los varios estudios que para esa fecha había realizado el antrópologo y afrólogo cubano Fernando Ortiz, a quien describe como "la más alta autoridad" en el tema negro (18). Es de notar que, a parte de su labor antropológica, Ortiz también había discurrido sobre la "poesía mulata" en las Antillas."

Con las garantías de credibilidad hechas a partir de la referencia orticiana acerca del supuesto "espíritu afro-cubano" en la Antología, Ballagas pasa luego a definir la llamada "poesía negra" como una entidad principalmente lingüística y cultural. La sitúa dentro de las fronteras de un universo panhispano separado y establece, además, que como constructo discursivo, esta poesía tiene antecedentes españoles, de hace cuatro siglos; "Lo negro empieza a ser en la península [ibérica], primero como humanidad, después como hecho

${ }^{5}$ Davis (224-225) señala la enorme influencia de este modelo comparativo de las relaciones raciales en las Américas que tuvo el trabajo de Frank Tannenbaum en 1947. Entre otros trabajos de influencia que antecedieron a Tannenbaum figuran el de Gilberto Freyre y Tomás Blanco.

- Se notan los siguientes artículos, publicados en la Revista Bimestre Cubana, "La poesía mulata: Presentación de Eusebia Cosmé", "Más acerca de la poesía mulata: Escorzos para su estudio" y "Los últimos versos mulatos". 
literario. La poesía negra que se cultiva en las Antillas hispánicas, en Cuba, Santo Domingo, y Puerto Rico, no es en su origen otra cosa que poesía española" (30).

Es curioso observar en la tesis ballaguiana que, mientras en la introducción a la antología que hizo en 1935 había privilegiado un acercamiento "serio" al tema negro, sobre otro superficial y de interés exótico y turístico, e inclusive había criticado el caricaturismo y las imágenes grotescas que caracterizaban la obra de los "dibujantes y escritores costumbristas de nuestras generaciones precedentes" (16-17), ${ }^{7}$ su discusión en 1946 promueve a escritores del Siglo de Oro español como precursores putativos de la poesía negra. Pero al incluir a estos autores (Luis de Góngora, Lope de Vega, etc.) en su antología, pasa por alto, aparentemente, el hecho de la burla del sujeto afroespañol que caracterizaba la presencia de los negros en dichos textos. De hecho, es a partir del conjunto de caricaturas y estereotipos negativos del afroespañol que aparecen en el teatro y la poesía del Siglo de Oro que se produjo la estereotipía del bufo cubano del siglo XIX que Ballagas ostensiblemente criticaba. Es decir que mientras proyecta título de propiedad sobre la poesía negra como producto cultural español, al autor le pasa inadvertida esta contradicción.

Procede Ballagas luego a restarle importancia a la identidad racial en la escritura de la poesía negra al sugerir que la verdadera poesía "no tiene color", criticando de paso el énfasis que algunos comentaristas habían puesto en las implicaciones sociológicas para con una etnopoética negra:

Esta expresión de la sensibilidad del hombre de color, pueden darla cabalmente el negro y el mulato desde su propio centro intuitivo lírico; e igualmente el blanco, pero por un fenómeno reflejo, tan diáfano a veces, que supone, no sólo una afortunada identificación, sino hasta qué punto el despojarse del lastre historicista y sociológico lleva de nuevo a la identidad de la especie humana y a la idea cristiana de su origen común ("Situación" 6).

El esfuerzo por definir el nombre y los términos de referencia del género, y por proyectar la noción de que los latinoamericanos negros y blancos tienen las mismas opiniones sobre la cuestión de las relaciones raciales en América Latina, delata, puede decirse, una intención de hablar "por el otro", con todas las implicaciones que esto conlleva. Es de notar que Ballagas, como escritor blanco de clase media, hablaba a partir de la situación de privilegio y poder a la que se asocian tradicionalmente los letrados en América Latina, ${ }^{8}$ y que en las dos décadas anteriores a la edición de su Mapa, eran poetas de

\footnotetext{
${ }^{7}$ Es de suponer que aquí Ballagas hace alusión al teatro bufo y al costumbrismo decimonónicos de escritores y pintores como José Betancourt y Víctor Landaluze cuyas obras incluían a los afrocubanos como materia paródica. Moore señala la influencia que tenían los minstrel shows estadunidenses en la década de 1860 sobre el teatro bufo cubano (248), mientras Fra Molinero hace la conexión histórica entre aquéllos y el negro cómico del teatro español del Siglo de Oro así como del teatro portugués contemporáneo (65-66).

${ }^{*}$ Linda Martin Alcoff en Who Can Speak: Authority and Critical Identity, ilumina la cuestión del poder y la localización del hablante al "representar" o "hablar en nombre de(l) otro:" "Cualquier declaración invocará las estructuras de poder asociadas con la posición social del hablante, a pesar de los intentos o esfuerzos de éste para evitar tales invocaciones: [A]ny statement will invoke the structures of power allied with the social location of the speaker, aside from the speaker's intentions or attempts to avoid such invocations" (105).
} 
ascendencia africana como Langston Hughes, René Maran y Aimé Césaire quienes estaban ocupando los sitios conspicuos en el firmamento literario internacional. Si se toma en cuenta el capital simbólico que habían generado internacionalmente los protagonistas de la négritude y del Harlem Renaissance y sus reclamos en pro de una alteridad cultural negra, no parece exagerado suponer que la proyección que Ballagas hace de una genealogía y una geografía distintas para la "poesía negra", con menoscabo de las tensiones sociales y la herencia colonial, puede verse como una reacción de ansiedad ante el prestigio y la audibilidad que estaba cobrando ese discurso panafricano del día.

Tampoco parece exagerado ver, tras su definición de un bloque cultural hispano distinto y separado como el centro matriz de la "poesía negra," deseos encubiertos de enfatizar una autonomía cultural dentro de la cual se preservaría el privilegio étnico para literatos blancos como era él mismo; y de ahí una plurietnicidad autorial para el negrismo que conservara el status quo tradicional. Esta aseveración se afianza en el hecho de que eran contadísimos los casos de afrolatinos en la historia latinoamericana que habían logrado superar los condicionamientos de su medio social y hacerse poetas. El esquema ballaguiano, en resumen, se aprovecharía así del mutismo impuesto en este sector subalterno y establecería a la vez la voz y el derecho de "representación literaria" para el escritor blanco de clase media.

Es también evidente en la estructura de las antologías antes mencionadas, que endosan la teoría de Ballagas al incluir o citar a Góngora o a Lope de Vega como "precursores" distantes de la "poesía negra". De hecho, muchos comentaristas no sólo aceptan sin crítica la teoría de este tipo de representabilidad interracial, sino que convierten la toma de voz y el presumido derecho del autor blanco latinoamericano para "representar lo negro", como base de competencia y jerarquización dentro del movimiento mismo.

Jerarquización y derechos de representación parecen ser las premisas que se encuentran tras la enfática declaración de Rosa Valdés-Cruz, de que: "Puede decirse sin lugar a dudas, que Palés Matos fue el que inició el período crucial del género..."(133). Así mismo, para Julio Marzán, fue Luis Palés Matos quién precedió e "hizo las movidas literarias que prepararan el camino para la emergencia de Guillén". " No hace menos Mercedes LópezBaralt al aseverar la primordialidad de Palés Matos por encima de poetas negros de renombre internacional como fueron McKay y Langston Hughes, al señalar que su poema "La danzarina africana" (1917-1918), antecedió las colecciones de Harlem Shadows (1922) y The Weary Blues (1926); describiéndolo, en fin, como el "iniciador indiscutible del negrismo en las Antillas hispánicas" (330).

Clama por señalarse, no obstante, que más allá del error historiográfico en la última declaración, ${ }^{10}$ está la voluntad de hegemonía del discurso crítico que se canoniza. Las interesadas interpretaciones "doctrinarias" responden a esta voluntad. Responden a ella también, el juicio negativo a las "lecturas descaminadas" acerca del negrismo de Palés

\footnotetext{
" "performed the literary moves that set the stage for Guillén to surface" ("The Poetry and Antipoetry" $511)$.

1" Como se indicó arriba "El grito abuelo", de José Manuel Poveda, lleva fecha de publicación de 1915 (González-Pérez 31) y "La comparsa" de Felipe Pichardo Moya (también cubano), de 1916. Los dos poemas llevan los paradigmáticos elementos de negro, tambor, y el supuesto atavismo del sujeto, que van a marcar la poética negrista.
} 
Matos, que hace López-Baralt (329), así como las ansias por establecer el status canónico tanto nacional como continental de este poeta y el salto insólito de convertir su temática caribeñista en gesto estrenador de la negritud. ${ }^{\prime \prime}$

II

El papel de la crítica neoliberal en cuanto a la producción de conocimiento y el mantenimiento de lo que Weedon llama las "formas deseadas" ("desired forms") de conciencia social conforme con el proyecto hegemónico (117-118), no sólo implica la proyección de Palés como el "poeta mayor" nacional (López-Baralt 330), y "primer cantor del mestizaje en nuestro país" (335). ${ }^{12}$ Este papel consiste también en idear la armadura interpretativa apropiada para con su obra negrista como se viene indicando. Tal como hace el gesto ballaguiano por eludir la cuestión del negrismo exótico y menospreciar la diferencia racial en esta poesía de temática racial, el discurso hermeneútico acerca de la obra palesiana, y de mucho del negrismo en sí, evita en gran medida un enfrentamiento con el racismo, o con las contradicciones de clase y género en un medio en el que estas contradicciones sobresalen. Antes bien este discurso tiende a sublimizarlas o escamotearlas, y llega a veces a ver una celebración y una reivindicación del sujeto negro cuando son evidentes el tono condescendiente, la hostilidad, la condescención y hasta el escarnio para con este sujeto.

La lectura de lo que la lírica palesiana proyecta bajo la etiqueta de la "majestad" negra se nos ofrece como un caso ilustrativo. Palés a través de poemas como "Bombo", "Majestad negra", "Lagarto verde" y "Elegía del duque de la mermelada", traza con ironía figuras de negros en posición de ascendencia social, como son los de la aristocracia poscolonial haitiana del siglo XIX ("Elegía" y "Lagarto"); de un imaginario líder tribal en el Africa subsahariana ("Bombo"); y de Tembandumba, compuesta de una mítica reina africana y una reina de comparsa en las que antes eran fiestas típicas afrocaribeñas.

Es de notar que a menudo el análisis de estos poemas por el neoliberalismo crítico, a pesar de que sí reconoce la ineludible ironía por parte de la voz poética, muestra una renuencia impresionante por calar en la relación entre los interlocutores que crean estos versos. Dicho análisis enfatiza los valores estéticos y estilísticos, y hace uso de la evasión y el eufemismo, descentralizando en fin, al sujeto humano (negro) de la discusión. Así viene a ser la difícilmente superada "calidad rítmica", o la "habilidad metafórica" del poeta, que subraya Jaime Benítez en la introducción a su edición del Tuntún $(12,14)$ o es la fina sensibilidad acústica de Palés como vanguardista, que se señala en la discusión sobre "la

"La négritude como movimiento poético e ideológico tiene contornos históricos y personajes bien definidos. Confundir el empeño identitario y emancipador de Leon Damas, Leopold Senghor, y Aimé Césaire (quien acuñó el término en 1934 en Paris) con una supuesta visión ideológica caribeñista palesiana, a duras penas puede explicarse a través del lápsus semántico como parece proponer aquí la crítica. Tampoco puede postularse que el "cimarronaje cultural" es lo que tienen en común estos poetas (López-Baralt 331), puesto que en ningún momento Palés Matos cuestiona la "trascendencia" del legado colonial español, o se desasocia de ella.

12 Dada la importancia de la mezcla racial indo-española como tema dentro del discurso literario puertorriqueño de la identidad cultural nacional, evidente en el siglo diecinueve y hasta bien entrado el actual (Zenón-Cruz t 1, 53-67) es controversial esa observación ya que limita el mestizaje a la mezcla blanquinegra. 
ironía como programa poético en el Tuntún palesiano" (López-Baralt 333). La evaluación que hace Margot Arce lleva esta tendencia a su punto culminante, al afirmar que el supremo artificio gongorino que Palés emplea presta "mayor agudeza" y produce una realidad superior en torno a sus negros líricos, que el tratamiento más banal y realista que hacen un Guillén o un Ballagas del sujeto (en Federico de Onís 16-17).

Es importante observar, sin embargo, que la ironía literaria, en cuanto partícipe de la comicidad caricaturesca, invoca irrevocablemente a sus referentes textuales y extratextuales, y que la lírica palesiana parte de un mundo concreto, y son reales los significados que crea. También es importante notar que dichos referentes constituyen una comunidad ya estrecha, ya extendida, de interlocutores, en la que se encuentran tanto el sujeto burlador y el burlado, así como el sistema de valores que el último supuestamente ha violado.

Según Freud, la ironización caricaturesca responde, entre otras cosas, a la necesidad de desenmascarar a aquel impostor que "se ha arrogado de la dignidad y la autoridad mediante la decepción", ${ }^{13}$ y de quitárselas. En tales ocasiones la solemnidad y el respeto que se reservan para el personaje de rango (ya genuino, ya fingido), son abandonados y son reemplazados por el proceso que busca degradar a dicho impostor (256).

Freud también subraya que el proceso caricaturesco y desenmascarador a menudo sirve a propósitos hostiles y agresivos, y que "nuestra risa expresa una sensación de gozo que se debe a la superioridad que sentimos en relación a él [el burlado]". ${ }^{14}$ En un contexto de dominación racial como es y ha sido el caribeño, el negro "parejero"15 que asume aires de nobleza francesa y que se viste con exagerada elegancia versallesca, se convierte en fácil blanco para la punzante ironía palesiana. Así es como la aristocracia del Haití poscolonial, arrastrada todavía por el mimetismo francófilo, viene a representarse en el verso palesiano a través de la metáfora simia, y los negros haitianos (de "Lagarto verde") son "tití(es)"(v.4), "macacos" (v.9) y "orangutanes" (v.32). Así mismo las "botas ducales" (v.15), y los "guantes de aristócrata" (v.19) que viste el "Duque de la Mermelada" en "Elegía" son inútiles para reprimir los impulsos atávicos de éste ya que su instinto "natural" es subir las cornisas del palacio, cual mono, y derribar violentamente a la igualmente "gentil" Madama de Cafolé, para una ronda sexual.

El "suculento asado de niño" que según la voz poética añora el "Duque" (v.5), apunta al mismo salvajismo, esta vez canibalesco, que va a caracterizar a Bombo en su reino de la selva congolesa. A este "mongo máximo" (v.9), cuyo poder "no tiene término" (v.20) y quien infunde terror a todos los otros jefecillos y brujos de la comarca, no le hacen falta los atavíos de la civilización, ya que él mismo representa la esencia del mítico salvaje africano que nos presentan las narrativas coloniales de viaje de los siglos XVIII y XIX (el escenario del poema se completa con los inevitables elementos de la fogata, con el blanco prisionero a comerse y los danzantes guerrilleros en su alrededor). ${ }^{16}$

1.3 “ $[\ldots]$ has seized dignity and authority by a deception" (257).

14 “ "[...] our laughter expresses a pleasureable sense of the superiority which we feel in relation to him" (255).

is A esta voz racista Tomás Blanco la describe como "sanamente eufemística" (12). Su compatriota Zenón-Cruz señala la ansiedad y el desdén expresados por los creyentes de la supremacía blanca, acerca del negro que no se mantiene en "su lugar" ( $\mathrm{T} 1,254,257)$.

${ }_{16}$ Pieterse describe esta imagen como el cliché "más gastado" ("worn out" 114) que ha empleado el humor occidental acerca de sus Otros. 
Sin embargo, lo principal de esta caracterización cómica-heroica del mongo máximo, cuyo fabuloso poder mágico domina no sólo las fieras selváticas sino a todos sus enemigos putativos, es que procede del ano y es capaz de trasmitírsele al que pretenda participar de su gloria, mediante una infusión por la boca:

¡Feliz quien bebe del pantano

Donde El sumerge su trasero! (vs 31-32)

Es importante indicar que el reconocimiento de la ironía y el humor palesianos por parte de la crítica, que no hace caso de la agresividad y la jerarquización entre los interlocutores que invoca, crea un texto que tiene sus propias implicaciones problemáticas. $\mathrm{Al}$ (re)crear con propósito humorístico a un Bombo primitivo, perezoso y prelógico, el cual es el antítesis (degradada) del estereotipo de la realeza occidental y la intelectualidad cartesiana, hay que señalar que el intento palesiano se dirige hacia aquella risa que para Jan Nederveen Pieterse "estigmatiza y por ende demarca las fronteras entre los mundos culturales". ${ }^{17}$ Este tipo de humor, hay que agregar, tiene un papel bien específico en la preservación de la cultura de la dominación (98).

Dadas la descentralización finisecular del antiguo régimen colonial español por el imperialismo de turno y las implicaciones para Puerto Rico de la ideología racial yanqui, no sería de sorprender una reacción de ansiedad por parte de su criollidad decadente (de la que formaba parte Palés). La clase antes dominante ahora tendría cada vez menos que la separase de los puertorriqueños pobres y culturalmente desposeídos. Esta sería la lógica que produce en el campo simbólico, la exageración de las diferencias sociales existentes ante dicha amenaza al status quo. En White on Black: Images of Africans and Blacks in Western Popular Culture, Pieterse nos indica que los "estereotipos se reconstruyen y se reafirman precisamente cuando las jerarquías están siendo retadas, y las desigualdades están disminuyéndo o parecen estarlo". ${ }^{18}$ Se aclara así la motivación tras la degradante caricatura de Tembandumba, la reina del carnaval, cuyas ampulosas proporciones físicas son hechas exactamente a la medida de su supuesto apetito sexual:

\section{Prieto trapiche de sensual zafra}

El caderamen, masa con masa,

Exprime ritmos [...] (vs. 11-13)

Como en el caso de Bombo, aquí el motivo cómico-heroico nos asegura que la majestad pasajera de Tembandumba, es también una majestad burlada.

Jaime Benítez, refiriéndose a los poemas "Topografía" y "Pueblo" de Palés, alude con acierto al desencantamiento isleño que provocara el imperialismo de turno. La falta de autonomía política y la nueva cultura y lengua impuestas en Puerto Rico a partir de la guerra hispanoamericana de 1898 , se aúnan al subdesarrollo y el provincialismo, y se evidencian

17 "[...] stigmatizes and thus demarcates the frontiers between cultural worlds" (98).

18 "Stereotypes are reconstructed and reasserted precisely when existing hierarchies are being challenged and inequalities are or may be lessening" (223). 
en la aridez y el sentido de derrota que caracterizan estos poemas. Ante ese ambiente abrumador sugiere Benítez que el poeta tiene que escaparse "por la escotillón del arte" (27).

Pero el motivo de escape de la enajenante situación colonial que apunta Benítez tiene otro aspecto para el hombre de cultura puertorriqueño. Lo expresa Emilio Belaval (a quien cita Benítez), como la angustia por emigrarse y dejar atrás no sólo el calor tropical, sino también la pobreza y la desconcertante mulatez:

El hombre sensible del trópico puertorriqueño, que ha tenido que quedarse, ha vivido bogando siempre en una barca de sueños fallidos, con la amargura de no poder marchar hacia tierras menos calientes, hacia paises más ricos, hacia áreas más civilizadas, hacia ciudades más blancas, hacia una zona más anchurosa, hacia una tierra más espiritual (20).

Si bien para Belaval, presidente en 1934 del Ateneo Puertorriqueño, la composición racial mixta de Puerto Rico resultaba tan desesperante, no parece haber sido motivo de inspiración tampoco para Palés Matos. A Palés pareciera resultarle tan difícil acomodarse a la presencia estadounidense como le fue acomodarse a la presencia física y cultural del puertorriqueño negro. De hecho es constante su referencia al conjunto cultural puertorriqueño mediante el despectivo término de "burundanga", señalando así cierta desilusión con una puertorriqueñeidad potencial venida a menos por el elemento afro."

Al mismo tiempo, al referirse a las otras islas caribeñas de población mayoritariamente negra como Martinica y Guadalupe en su "Canción festiva para ser llorada", la voz palesiana las feminiza, manteniéndolas "negras" que son, en ese papel servicial que les dictara el legado colonial; "Martinica hace la sopa", dice, y "Guadalupe la cama" (vs. 8-9), "Que Guadalupe me aguarda" (v.11). Significativamente, es el donjuanismo criollo de clase esclavista que sale a flor cuando hace referencia a la mulata como "amor sin trabas y sin prisas" ("Mulata-Antilla" v.44), y la altivez y el tono condescendiente ponen en entredicho su aparente intención democrática al hablar de la ascendencia mixta de ésta en "Ten con ten". Aquí es clara la voz poética al estipular que la mulata, pasaría "Por civil y ciudadana" (v.25), si no oliera tanto a "negra". ${ }^{20}$

Puede decirse en conclusión que en la medida en que el neoliberalismo cacarea el supuesto liberalismo de Palés Matos para con la "negritud", y sublimiza el humor de éste, es importante recordar que para el vate mismo, la geografía negra que inventa (Nigricia), es ficticia. En cuanto discurso literario, indica el autor mismo en el poema que introduce el Tuntún, que el libro que entrega a sus lectores comprende: "Poco realmente vivido/ y mucho de embuste y de cuento" ("Preludio en Boriqua" vs. 53-54). Puede decirse acerca de dicho discurso, que aunque resulta relevante el apunte que hace Freud de que "lo cómico emerge y se desvanece según el punto de vista de cada individuo", ${ }^{21}$ no hace falta invocar

19 El glosario de Alvarez Nazario describe el término de origen africano como "mezcla o revoltijo de cosas inútiles o de poca importancia; cosa despreciable, porquería [...]" (324).

${ }^{20}$ Zenón-Cruz subraya el papel reificante del diccionario como texto, al señalar la asociación racista que hace el Diccionario real de la academia española entre el "olor desagradable", y los "negros desaseados" (111).

21 "[...] the comic emerges and vanishes according to the standpoint of each particular person" ("Jokes and the comic" 261). 
el sicoanálisis para comprender la dinámica interlocutoria del humor palesiano. El elemento lúdico y agresivo (burlón) que encierra la libre creatividad del "embustero", es un fenómeno bien conocido tanto en la tradición oral africana como la española.

A la luz de esto, parece válido preguntarse acerca de los objetivos de la crítica que insiste en justificar la burla que el poeta hace de los pueblos negros o de los putativos nobles haitianos, como si la verdadera esencia de su aristocracia "macaca", se encontrara en el salvajismo canibalesco que el texto opone a su conducta pretenciosa (véanse por ejemplo a Valdés-Cruz 143, Thomas 32, Benítez 37, González-Pérez 290, y López-Baralt 331). Vale preguntarse también: ¿a qué vienen las sugerencias de que la supuesta deglución canibalesca de los "exploradores y misioneros" por una Africa mítica que se hace en "ÑamÑam" (vs. 11-12), representa realmente una afirmación de "resistencia cultural" por parte de los "guerreros africanos?" (véase Thomas 32).

III

Si bien podemos decir que la construcción canónica y hermeneútica del negrismo, a partir de sus poetas principales (no-negros) representa una apropiación del movimiento basado en la premisa de la plurietnicidad autorial, el mismo proceso a nivel antológico también manifiesta el principio hegemónico, ya que el conjunto antológico "negrista" no deja constancia de la obra de la mayoría de los poetas negros de América Latina. El celebrado Nicolás Guillén, como es sabido, es un caso excepcional. ${ }^{22}$ Es decir que al convertirse en categoría literaria historiográfica, el movimiento en gran medida desplaza a estos últimos y los hace o invisibles, o materia de investigación especializada. Más importante aún, al ocupar el espacio del otro, o "representarlo", esta trayectoria discursiva le quita la palabra y en consecuencia tiende a hacer irrelevantes declaraciones potenciales de alteridad discursiva étnica. Es decir que el proceso canonizador, como gesto de la cultura dominante, al apropiarse de los signos de la alteridad negra, tiende hacia una manipulación y neutralización de estos signos. El negrismo como fenómeno extratextual también manifiesta estas características.

La multidimensionalidad del negrismo es evidente tanto en el dibujo y la pintura del día, en formas músico-danzarias como el son y la rumba, en composiciones sinfónicas y teatrales, y en la primera novelística de Alejo Carpentier. Si bien su significado histórico en términos de la definición cultural de la nación cubana, radica en la incorporación y aceptación del legado cultural africano como parte intrínseca de esta definición, es importante subrayar que como evento cultural, en ese negrismo multigenérico, no fueron los portadores del legado cultural africano sus promotores, beneficiarios o protagonistas principales. Antes bien, el papel del sujeto negro era de materia prima en un proceso de comercialización marcada, y de objeto abstracto en las representaciones simbólicas del movimiento.

${ }^{22}$ El estudio de Edward Mullen (Afro-Cuban Literature: Critical Junctures 1988) nos informa que de cien antologías generales de poesía hispanoamericana publicadas entre 1940 y 1980, sólo se incluían a dos poetas negros; Nicolás Guillén, y el también cubano Plácido de la Concepción Valdés (167). La cubana Nancy Morejón ha sido incluída en algunas antologías universitarias recientes. 
Así los famosos cuadros y dibujos de Jaime Valls Díaz representando a figuras negras asociadas con la música y el baile afrocubanos, complementan los óleos inspirados en la santería y las comparsas que también hicieron famoso a Eduardo Abela en París y luego en Cuba. De igual forma, en un proceso que a menudo hizo uso del plagio y el fraude abiertos a músicos negros de la calle, géneros musicales afrocubanos como la rumba y el son tradicionalmente marginados - fueron catapultados al status de apasionada boga internacional durante los años treinta y cuarenta. La carrera del pianista y compositor blanco, Eliseo Grenet, de formación clásica, quién adaptó la música de las comparsas afrocubanas para los salones y cabarets franceses, y mediante una enérgica promoción mercantil, inspiró la manía de la conga en los años treinta en Francia, Inglaterra y en Estados Unidos, emerge así como un caso paradigmático del momento afrocubanista (Moore 73-78, 107,187).

Una de las ocasiones más notorias para ese proceso generalizado de "acercamiento cultural" se dio en el año de 1937 con la reautorización de las comparsas afrocubanas para el carnaval tradicional de febrero, y con ello su elevación al status de "folklore oficial". El momento deriva su importancia del antecedente de persecución persistente que habían sufrido ésta y otras parecidas manifestaciones de cultura afrocubana durante y después de la colonia, y la manera en que es apropiada o "legitimizada" por el estado neocolonial, perdiendo así gran parte de su carácter oposicional y su alteridad. Tras campañas en la prensa finisecular condenando estridentemente las prácticas de la santería y sus seguidores por bárbaros y dañinos a la imagen de una Cuba civilizada, y prohibiciones a nivel municipal y nacional, ${ }^{23}$ es el mismo alcalde de La Habana, Antonio Beruff Mendieta quien en 1937, con el endoso entusiasta del Dr. Fernando Ortiz, presidente de la recién formada Asociación de Estudios Afrocubanos (1936), reinstala la celebración callejera y, reconociendo su importancia para el turismo como "segunda industria" (Mensaje 21), ofrece "premios en metálico" a los grupos más destacados ("Comunicación" 7).

El resurgimiento de las comparsas viene acompañado por la retórica orticiana señalando la necesidad de conservación de las "viejas costumbres folklóricas" ("Informe", 10 ), tal y como la hacen los (otros) países civilizados como España e Inglaterra, y para el caso cubano, "a pesar de sus elementos intrínsecos de barbarie" (Informe 12). Para el contexto es imposible pasar por alto no sólo el poder legitimizante de Ortiz como antropólogo afrólogo al dar el visto bueno al proyecto del alcalde Mendieta, sino también el oportunismo económico del municipio para con una cultura antes vigorosamente oprimida, y el papel del mismo Ortiz en la demonización finisecular de dicha cultura. En el informe del Dr. Ortiz al Sr. Alcalde en el que se pronuncia a favor de las comparsas, se subrayan tanto el "valor artístico" de dichas comparsas, como sus "enormes posibilidades [...] para atracción del turismo y sus mercantiles provechos" (Hampa afrocubana 14).

El contraste con el llamado que hizo Ortiz en 1906 para la "eliminación social" de los babalaos como funcionarios de la santería afrocubana (242) y de todo lo asociado con el

2.3 Véase, por ejemplo, a Helg (111-116). Moore cita ordenanzas municipales expedidas por los doctores alcaldes Nicasio Estrada Moro (1900), y Fernando Freyre de Andrade (1913), prohibiendo las comparsas, los tambores de origen africano, así como los bailes "inmorales" y "lascivos" a ellos asociados. Se aplica la prohibición a nivel nacional por decreto presidencial de Gerardo Machado (6672). 
supuestamente atávico legado cultural afrocubano, su aparente cambio de opinión sólo puede atribuirse a su conocimiento más directo de esa cultura, al prestigio internacional que estaba cobrando la boga negra, así como el mismo consensus generado en el discurso intelectual de vanguardia acerca de la relevancia de lo afro para con la identidad cultural nacional. ${ }^{24}$ A partir de ese momento hasta la actualidad posrevolucionaria no se cuestiona la premisa de la hibridez cultural nacional afroespañola en Cuba, más bien, se la celebra.

El negrismo poético emerge, entonces, como un movimiento análogo a otros gestos culturales antillanos "negrófilos". Estos se manifiestan a través de las artes plásticas, la comercialización de la rumba, la conga y el son tradicionales, aunados al siempre despectivo teatro vernáculo. Son la orientación acústica de su versificación, la plasticidad de sus imágenes y su temática folklórica y músico-danzaria, lo que para muchos críticos van a definir el "negrismo" del negrismo (véase por ejemplo, Mónica Mansour, "Circunstancia e imágenes de la poesía negrista"), y dan pie a lo que para ellos constituye la "autenticidad" del verso negro por poetas blancos.

Pero es la misma concentración del género en el negro como espectáculo - tan evidente en el alto porcentaje de poemas que representan comparsas y bailadores de rumba, por ejemplo ${ }^{25}$ - el enfoque detenido del ojo poético en los rasgos físicos del negro, cual novedad, y la repetida y estereotipada hipersexualidad de la mulata, lo que en conjunto marcan al sujeto del negrismo como Otro étnico en un discurso mayoritariamente transracial que se cuida de mantener las diferencias culturales. La referida burla palesiana, la muy comentada estereotipía negativa aplicada al sujeto (véanse los trabajos de Jackson, Johnson, y Kubayanda) y la recurrente referencia sintáctica de la voz poética marcando al sujeto bajo la categoría de "ellos", es evidencia fehaciente de esto.

Si bien la calificación que hace Depestre del movimiento como una "verdadera aculturación de la herencia africana" por intelectuales blancos (23), apunta hacia un deseo por parte de los poetas eurocaribeños por franquear las barreras raciales legadas por el colonialismo, sería simplista si no francamente erróneo ver en este fenómeno un reto al racismo, o una perspectiva negra "desde dentro". El negrismo multigenérico como habitación temporaria del espacio cultural negro por el Otro blanco, debe verse a partir de una realidad sociopolítica que para la mayoría de cubanos de ascendencia africana, fue marcada por la pobreza y la discriminación en el campo laboral, así como la exclusión y segregación en muchos sitios como fueron playas y parques públicos, por no hablar de una posible reivindicación política. ${ }^{26} \mathrm{El}$ discurso literario de clase media que se entretenía en el

\footnotetext{
${ }^{24}$ Mullen ("Los negros brujos" 115) y Moore ("Representations" 33) nos informan que Ortiz había pasado apenas cinco años de su vida en Cuba al escribir Hampa afrocubana: los negros brujos (apuntes para un estudio de etnología criminal).

${ }^{25}$ Entre los títulos sobre este tema en la antología clave de Ramón Guirao figuran; "Bailadora de rumba," "La rumba", de José Zacarías Tallet, "Rumba", de Emilio Ballagas, "Rumba" de Alfonso Hernández Catá, "Rumba de la negra Pancha", de Antonio Portuondo, y "Rumba de tumba y dale", de Vicente Gómez Kemp.

${ }^{26}$ El justificado pero fallido intento por una reivindicación politica negra a través del Partido Independente de Color, inevitablemente formaría parte de la memoria colectiva durante la época negrista. El sangriento aplastamiento de los líderes, seguidores y supuestos seguidores de este movimiento en 1912, merece el calificativo de "masacre" según la opinión de Helg ( 5 \& ss).
} 
retrateo pintoresco poca atención prestaba a esas condiciones objetivas de la vida del sujeto. Por otra parte, el teatro bufo, como la forma más extrema de la boga multigenérica, y con los malsanos estereotipos del "negrito", y "la mulata", claramente demuestra el poder distorcionador del gesto transracial caracterizado por la nociva práctica del blackface en Cuba. ${ }^{27}$

La ambigüedad que marca la reacción de los profesionales negros y mulatos nos da una idea clara de cómo fue recibido el arte transracial por una parte de la comunidad negra. Alarmados por el abrazo selectivo e interesado de las comparsas por las autoridades políticas e intelectuales, y sensibles al estigma social que para ellos conllevaban las manifestaciones populares negras, la incipiente clase media negra se refugia en el discurso asimilacionista, enfatizando su cubanidad esencial y subrayando su diferencia con el Africa y lo africano. Es de suponer que el llamado por la división del país según líneas raciales, hecho en 1934 por la Confederación Nacional Obrera de Cuba, se añadiría a este sentido de alarma. Es el deseo, entonces, por no perder los logros sociales, pero tampoco dejarse retroceder al negativo marcador socio-étnico negro, lo que motiva aparentemente a un escritor como Alberto Arredondo a rechazar enérgicamente el afrocubanismo, alegando que el espectáculo negrista, por oportunista e injusto, inhibía el proceso de integración racial que tanto necesitaba la nación.

Arredondo expresa su opinión en el artículo "El arte negro a contrapelo" de que la boga afrocubanista distraía la atención de la resolución de los verdaderos problemas sociales. Aseveró además que más valía al negro cubano “ 'arrollar' conjuntamente con el blanco en el camino de las posibilidades económicas", que tras la comparsa (5). En otro momento se lamenta de la resurrección del fantasma de lo que llama el "superado" folklore musical negro, por sus nuevos intérpretes no-negros.

En la medida en que la plurietnicidad del negrismo en cualquiera de sus manifestaciones ejemplifique el funcionamiento del poder en la representación, y la legitimización de la expresión subalterna en la articulación de un consensus nacional, es importante tomar en cuenta el papel y el impacto del poeta mulato Nicolás Guillén, como parte de este proceso. Aunque el espacio no permite un análisis de este papel, está claro que no sólo es por la calidad de sus versos, sino también por el compromiso ideológico, que se erige como poeta nacional y presidente de la Unión Nacional de Escritores y Artistas Cubanos durante décadas. La reivindicación del legado cultural africano que hace en el prólogo a sus "versos mulatos" en 1931 (Sóngoro Cosongo), y la desinhibida celebración de las garantías de la nueva Constitución socialista que hace a través de su personaje negro, en el poema "Tengo" de 1964, por ejemplo, establecen el nexo histórico entre el período antes y después de la revolución, por el cual se solidifica el discurso identitario nacional bajo el término birracial.

La magnitud de la tarea histórica antirracista, sin embargo, se revela a través de las apreciaciones más optimistas acerca de la situación racial cubana. Para Nancy Morejón, decana de la generación actual de poetas negros en Cuba, en una discusión en la que hace

\footnotetext{
${ }^{27}$ En Racechanges, Susan Gubar hace un análisis detenido del poder y privilegio implícitos en ésta y semejantes formas de representación de la sujetividad negra por blancos. Moore nos informa que el Blackface cubano formaba la base de las carreras de múltiples actores durante la era negrista (48), indicando además haber presenciado un espectáculo tal en fecha tan reciente como 1992 en La Habana (151).
} 
referencia a Guillén como "el poeta cubano de más alta conciencia nacional en el siglo XX, que clama por la realidad mestiza de la cultura del país" ("Transculturación y mestizaje en Nicolás Guillén" 68), es evidente la nota tentativa cuando declara que "todos somos cubanos y nos preocupa cada día menos [...] el deslinde entre una raza y otra" (79). En ésta, como en otras discusiones y en el mismo quehacer poético, es de notar que es el marco retórico oficial lo que cobra primacía, y que el discurso etnopoético (negro), que indudablemente se maneja, vive sujeto a una negociación cuidadosa.

De la problematización del negrismo canonizado y la alusión a una diferencia autorial y discursiva negra, surge inevitablemente la siguiente pregunta: ¿en qué consistiría, entonces, un hipotético canon poético afrolatino? Suponiéndole validez a la pregunta, su respuesta tendría por lo menos dos partes. ${ }^{28}$ La primera está relacionada con la tendencia de ver el negrismo a partir de una proyección discursiva historiográfica que lo sitúa como el momento "culminante" de otros gestos precursores, tales como un poema aislado de Rubén Darío ("La negra Dominga", 1892 ), o "La mulata" de Francisco Muñoz del Monte (1845), o bien el teatro y poesía del Siglo de Oro español mismo (véase las antologías mencionadas arriba). Como se ha notado, el motivo del mestizaje que surge de este análisis escamotea la dinámica del poder en las relaciones socioraciales. Asimismo como procedimiento analítico, subordina la presencia y la conciencia del escritor negro a consideraciones de otra índole.

Una apreciación alternativa se dirigiría hacia el rescate de aquellas voces desconocidas, ignoradas u olvidadas que preceden y que siguen al negrismo canonizado. En esta apreciación cobrarían primacía la presencia y conciencia del poeta negro en nombre de su derecho a autorrepresentarse y por lo que pudiera aportar su discurso en cuanto a un mejor conocimiento de las realidades americanas "historicoexistenciales". De hecho, en esta tarea recuperadora se han ocupado varios estudiosos como son Richard Jackson, Marvin Lewis, Ian Smart, Laurence Prescott, y Miriam da Costa Willis. ${ }^{29}$

El segundo aspecto de una recuperación o compilación canonizante para con la poética afrolatina, se relacionaría con la organización crítica y hermenéutica de este cuerpo de textos, ya sea en términos de su propio marco epistemológico, o en términos de la práctica literaria en América Latina vista en su totalidad. Evidentemente los procesos que justiprecien estas obras - para usar un término de Enrique Anderson Imbert-o que establezcan su "excelencia canónica", no son fáciles de decidir, ni susceptibles a una determinación de antemano. No por eso dejan de ser importantes. Como cualquier proceso

\footnotetext{
${ }^{28}$ El ensayo de Vera Kutzinski publicado en la Cambridge History of Latin American Literature, por ejemplo, no ve ninguna relevancia en la noción de un canon literario afrohispano que sea distinto del canon general (166-168).

${ }^{29}$ Aparte del trabajo de crítica y de historiografía en que estos estudiosos abarcan a autores de varios países en Hispanoamérica, vale notar el empeño bibliográfico de Jackson por ejemplo en The AfroSpanish American Author II: The 1980s, y la primera antología de poesía escrita por afrolatinas, Daughters of the Diaspora: Afro-Hispanic Writers, que está siendo preparada por Miriam DaCosta Willis.
} 
de valorización literaria historiográfica, entrarían en juego tanto lo estético, como lo ideológico.

Al hablar recientemente Richard Jackson en Black Writers and the Hispanic Canon, acerca de la importancia del motivo racial en la obra de los escritores afrolatinos, comentó de forma indirecta el cargo de esencialismo que hacen algunos críticos ante la mitificación de un Africa ancestral por parte de estos poetas, o su proyección de una comunidad experiencial transnacional en torno a su africanía, es decir, su llamada "estética" negra (19). Las observaciones de Jackson llaman a la atención la resistencia a la diferencia que el discurso dominante opone a la perspectiva del sujeto negro acerca de sus propias experiencias, y las implicaciones que esta perspectiva tiene en cuanto a la representación de la dinámica socioracial latinoamericana del pasado y del presente. Dicha resistencia, cabe observarse, es parte intrínseca de la cultura de dominación, ya que en la medida en que el hecho racial expuesto en voz negra contradiga las versiones oficiales acerca de los temas de la hibridez y la coexistencia racial, estas voces se topan con el acallamiento y la devaluación de sus verdades.

Un ejemplo típico de tal resistencia y devaluación fue notado por Hoyt Fuller cuando recordó la evaluación hecha en 1963 de la obra de la poeta afroestadounidense, Gwendolyn Brooks, por un crítico del mainstream. Con la aseveración de que "si el ser negro es el único tema, no puede ser importante la escritura" ([...] if being a Negro is the only subject, the writing is not important), condenó ésta y por implicación toda la escritura de artistas negros que enfatizaran el motivo racial. Fuller, al comentar dicha evaluación, estuvo en lo correcto en ubicar su origen en el prejuicio, y en señalar que tales declaraciones sugieren que una temática específicamente étnica (negra), carece de trascendencia simbólica o de aplicabilidad "universal" (5).

Aparte de hacer notar la tendencia ya desaprobante, ya asimilacionista de la ideología racial dominante, la observación de Fuller descubre, además, la manera en que los portavoces de esta ideología distorcionan la realidad histórica, porque al convertir la conciencia racial en el sujeto (racializado) en objeto de crítica, confunde las causas con sus efectos. Es decir, el discurso dominante hace caso omiso del hecho de que fue la misma condición racial - los rasgos epidérmicos y morfológicos que marcan al sujeto como diferente- la que lo hizo susceptible a la acción discriminatoria en primer lugar. El sentido reaccionario de tales juicios, ante el hecho de un discurso contestatario que está siendo articulado por voces subalternas que habían sido calladas durante mucho tiempo, se revela así por lo que es (véase al respecto, Henry Louis Gates, "Writing Race and the Difference it Makes").

Si bien el concepto "raza" es un constructo historico-social, y por ende "fluido" o sujeto al cambio, no hay nada casual en el sistema de dominación social que utiliza la jerarquización racial como sostén ideológico. En última instancia, su objetivo es el poderío material y simbólico, aunque sean sujetas a cambio las formas por las que el status quo se mantiene. De ahí que la víctima de la discriminación racial sea en cierto sentido "preso" de su condición epidérmica o de todo aquello que señale su otredad (véase Stuart Hall, "Race: The Floating Signifier", al respecto). El impacto de este aspecto del proceso de la construcción de la identidad en el sujeto (es decir de una negritud "impuesta" desde fuera y a partir de la mirada del Otro) es de gran importancia. En un contexto como el de la sociedad colonial 
latinoamericana de castas, en la que el color oscuro de la piel atraía asociaciones con la esclavitud y era motivo de una marginalización multilateral, sería ilógico que el factor étnico en la identidad no se expresara en el discurso poético. ${ }^{30}$

De hecho, en uno de los poetas afrolatinos del que más tempranas noticias tenemos, José Vasconcelos (muerto en 1770), el tema de la identidad a nivel individual (racial) y a nivel colectivo (nacional), es el que domina en la pequeña muestra de sus versos que ofrece la antología de Mansour y González. Aparentemente, para "El Negrito Poeta" —nótese el seudónimo racial — ser de raza "conga" y de "nación mexicano" significaba identificarse bajo términos mutuamente excluyentes. Esto explica la necesidad por el hablante en el poema, de afirmar la nacionalidad tres veces en un breve cuarteto.

\section{Aunque soy de raza conga \\ Yo no he nacido africano; \\ Soy de nación mexicano \\ $\mathrm{Y}$ nacido en Almolonga}

Se nota que aquí, a pesar de que la voz lírica sí reconoce el origen africano en el sujeto, queda claro en los otros cuartetos de Vasconcelos, poeta popular improvisador, que la piel negra es algo por la que debe disculparse; un defecto por el cual se debe compensar para ser integrado plenamente a la sociedad:

\section{Ser negro no es culpa mía \\ A todos doy alegría \\ $\mathrm{Y}$ con esto me reintegro}

En 1995, más de dos siglos después de la muerte de Vasconcelos, la problemática de ser y de pertenecer que entrañan los principios de raza y nación aún era tema de gran preocupación para el poeta dominicano Blas Jiménez. Ante la aguda realidad de la marginalización y de las presiones asimilacionistas, Jiménez se niega a suscribirse a la noción de "una humanidad abstracta, irreal, e incolora" (6), cuando "los estereotipos, las miradas, las carcajadas, las zancadillas" comprueban a diario un imaginario dominante envenenado por el principio racista (5). Es decir que, a pesar de la diversidad temática y los otros determinantes espaciotemporales que puedan ser evidentes en la obra de éstos y otros poetas afrolatinos, es de inegable relevancia el hecho del acoso racial, que de una u otra forma marca sus conciencias y por ende, sus obras.

La consideración del tema de la raza y nación lleva a tomar nota de que quizá el legado ideológico principal del poeta cubano, Nicolás Guillén, haya sido su contribución a la legitimación del concepto "mulatez" en el discurso identitario nacional. La promoción de una cubanía birracial hecha por Guillén a través de las décadas, ha sido acogida y apreciada a tal grado que el valor simbólico de este motivo en su obra se ha proyectado más allá de los referentes meramente literarios. La crítica Mirta Aguirre, por ejemplo, acude a criterios

\footnotetext{
${ }^{30}$ El poema "Incident" de Countee Cullen, poeta afroestadunidense del Harlem Renaissance, es un ejemplo dramático del tema de la mirada del Otro y de la socialización de los niños blancos en los valores del racismo. The Norton Anthology of African American Literature (306).
} 
biológicos al afirmar la trascendencia de Guillén como poeta nacional, señalando que en comparación con José María Heredia y José Martí, los otros poetas nacionales, "ser mulato de carne y de alma," le hace a Guillén aún "más completo" como cubano. Sugiere que el conocido antirracismo de Martí, el Apóstol de la revolución cubana, sólo equivaldría a una mulatez de espíritu, y que ante Heredia, es el aferrado y comprometido nacionalismo del poeta camagüense, lo que sobresale (Morejón, "El concepto de la nacionalidad" 26).

En el contexto de claramente delineados protocolos de intelectualidad y de expresión literaria en Cuba, el comentario de Aguirre es importante. Si bien los conceptos de nación y mestizaje van de la mano en Cuba posrevolucionaria, es la misma lógica de la revolución la que dicta que por cuestiones de seguridad, lo nacional supere cualquier interés partidario o "racial". ${ }^{31}$ Los efectos de esta premisa sobre la escritura afrocubana no han dejado de notarse. Al contrario, se hace evidente un proceso de a veces difícil acomodación entre los intereses del estado y lo que pudiera leerse como el partidarismo étnico en el discurso de los poetas negros.

El asunto de la temática étnica en el discurso poético afrocubano posrevolucionario, y la cuestión de la censura o de la autocensura que de él se desprende, es puesto bajo relieve por los críticos que han estudiado los momentos de conflicto con las autorieades evidentes en la obra de nancy Morejón. Morejón es la poeta cubana que actualmente goza de más renombre internacional y su trayectoria poética ha sido marcada por momentos de abstracción y de hermetismo, así como un largo y conspícuo silencio entre los años de 1967 y 1979 (Howe, Luis). A pesar de su adhesión a la retórica oficial en su obra poética y ensayística, se le ha percibido un cuestionamiento del orden imperante y una codificación de sus inquietudes en relación a la actual estructura de poder en Cuba. Su celebrado poema, "Amo a mi amo", por ejemplo, ha sido leído desde este punto de vista.

El tema del poema trata de la relación amorosa entre un amo y una de sus esclavas, y el proceso de la toma de conciencia de la última, que la lleva a su asesinato. Es evidentemente una reivindicación del papel de la mujer esclava en la época colonial y de su agencia histórica. Pero se ha opinado que en la medida en que el poema utiliza la alegoría nacional de la esclavitud de plantación para criticar el pasado colonial, "Amo a mi amo" también logra poner en entredicho el patriarquismo vestigial en la actual dinámica de poder en Cuba (Conrad James 165). Es decir que la práctica del enmascaramiento como componente estratégico del discurso subalterno, permitiría a Morejón, en este caso, conformarse a los dictados del discurso oficial marxista, y a cuestionarlos a la vez.

Es dentro del mismo espacio que el discurso oficial del sincretismo abre con respecto a los elementos constitutivos de la nación cubana, que también encontramos celebraciones del precepto africano en una forma que es difícil de imaginar en décadas pasadas. La obra de Georgina Herrera se inserta en esta abertura. A través de poemas como "Fermina Lucumí" y "Africa" $(14,17)$, Herrera hace conspicuas a la mujer esclavizada y al Africa ancestral de forma tal que estos temas recuperan su debido lugar en el referido y muy evocado debate acerca de la hibridez cultural.

\footnotetext{
${ }^{31}$ Es bien conocido el dictamen castrista que estableció este criterio al discurrir el Comandante sobre el tema de la libertad del arte y la revolución. El llamado se hizo a fin de que los escritores cubanos revolucionarios pusieran "la revolución por encima de todo" 404, y asentar que dentro de la revolución cabía "todo; contra la revolución, nada" 406.
} 
Como "Amo a mi amo", "Fermina Lucumi" habla de la economía libidinal en la colonia y la relación entre amo y esclava que lleva a la muerte del primero a manos de esta última. El texto narrativo del poema se fija en los breves momentos antes del fallecimiento de Fermina a resultas de los latigazos con que la castigaron. Aunque el poema deriva mucha de su fuerza emotiva de la violación sexual que sufrió el sujeto, este tema es expuesto de modo más bien tenue (se le refiere como la "desventura del personaje" v. 21). Lo que sí se destaca es la condición general de la mujer esclavizada, es decir, su exilio, su cosificación y la pérdida de su dignidad. Así el texto recupera el acto de Fermina como una legítima defensa, y celebra su valor ante el reto mortal de su cautiverio. Es típico del estilo eufemístico de Herrera que termine el poema lamentando "que no exista una foto de sus ojos" (v. 22), porque "habrán brillado tanto" (v. 23).

En "Africa" Herrera vuelve al eufemismo cuando su voz poética adopta un tono de solemnidad casi religiosa al elogiar la tierra ancestral africana y al abarcar el tema usando aparentemente inofensivas imágenes de maternidad y domesticidad. No obstante la nota intimista y conversacional, es fuerte el enunciado con que empieza el poema y parece dirigido a contrarrestar el milenario discurso antiafricanista condenatorio - "Cuando yo te mencione/ o siempre que seas nombrada en mi presencia/ será para elogiarte" (vs. 1-3). Asimismo, la hablante da constancia de su compromiso con el Africa, al postular su relación con ésta en términos de estrechez, de permanencia, y de solidez, "Junto a ti permanezco, como el pie/ del más grande árbol" (vs. 5-6). De la declaración de solidaridad pasa el sujeto a un momento de reflexión, en la que mediante imágenes líquidas - de "lágrimas" y "ríos" (vs 8-9) - se produce un enfrentamiento cara a cara entre el sujeto y su referente, también personificado, que permite su identificación mutua como el mismo ente.

De la evocación que Herrera aquí hace del tema del ser humano como barro, procede a complicar la metáfora de identificación a través del tropo maternal, efectuando así, no sólo una identificación telúrica del sujeto con el lugar de origen, sino la evocación de una geneología y del marco matrifocal que gobernaba muchas sociedades tradicionales africanas. Pareciera que esta evocación de una línea sanguínea busca erigirse como una diacronía inviolada, ante la diáspora y la trata transatlántica. La referencia a los hijos de la hablante así reforzaría el tema de la continuidad, como también hacen las alusiones a una cosmovisión antigua que se preserva a través de la tradición oral. El poema, en fin, tematiza el continente africano en términos tanto míticos como empíricos y lo humaniza en forma de anciana dañada por las vicisitudes de la historia y del tiempo. Así cobra más valor emocional para la hablante. Esta, a su vez, adopta un papel de guardián comprometido al cuidado de la referente y empeñada en que "nadie olvide que está[s] viva" (v. 17).

En conclusión, podemos decir que en la medida en que estos poemas recrean la economía sexual de la colonia, desmitifican, por una parte, el discurso de un mestizaje romántico que pierde de vista las relaciones históricas de poder en que dicho mestizaje se dio. Por otra parte, al insistir en la identificación africanista y en la integridad incontaminada del precepto africano, como parece hacer Herrera en "Africa", asientan las bases para un debate de la hibridez, que partiera de la premisa de la igualdad. Es decir que, al hablar de negrismos, ya sean "desde dentro" o "desde fuera," si bien sería un absurdo invalidar el principio de la representabilidad interracial (ya que no existen barreras a la imaginación humana), se pecaría del utopismo enajenante al no reconocer los contornos de la política de la representación. 


\section{Bibliografía}

Albornoz, Aurora de, Julio Rodríguez-Luis. Selección de textos, introducción crítica, vocabulario y bibliografía. Sensemayá: La poesía negra en el mundo hispanohablante (Antología). Madrid: Editorial Orígenes, S.A., 1980.

Alvarez Nazario, Manuel. El elemento negroide en el español de Puerto Rico. San Juan de Puerto Rico: Instituto de Cultura Puertorriqueña, 1961.

Arredondo, Alberto. "El arte negro a contrapelo". Adelante: Revista mensual 3/26 (1937): 5-6, 20. 5-6.

Ballagas, Emilio. Cuaderno de poesía negra americana. Santa Clara, Cuba: Imprenta La Nueva, 1934.

Antología de la poesía negra americana. Madrid: Bolaños y Aguilar, 1935.

"Poesía negra liberada". Revista de la UNAM 18 (1937): 5-6.

"Situación de la poesía afroamericana". Revista Cubana 21 (1946): 5-60.

(ed.). Mapa de la poesía negra americana. Buenos Aires: Editorial Pleamar, 1946.

Benítez, Jaime. "Prólogo". Tuntún de pasa y grifería. San Juan de Puerto Rico: Biblioteca de Autores Puertorriqueños, 1974.

Beruff Mendieta, Antonio. "Mensaje del Alcalde, doctor Antonio Beruff Mendieta, al Ayuntamiento, informando sobre los trabajos del Departmento de Turismo y su Comisión Asesora". Las comparsas populares del carnaval habanero, cuestión resuelta. Ed. y prefacio de Antonio Beruff Mendieta. La Habana: Molina y Cia., 1937. 21-28.

"Comunicación del Alcalde de la Habana al Presidente de la Sociedad de Estudios Afro-cubanos, solicitando la opinión y el consejo de dicha sociedad sobre el resurgimiento de las comparsas populares habaneras". Las comparsas populares del carnaval habanero, cuestión resuelta. Ed. y prefacio de Antonio Beruff Mendieta. La Habana: Molina y Cia., 1937. 7-8.

Blanco, Tomás. El prejuicio racial en Puerto Rico. San Juan de Puerto Rico: Editorial Biblioteca de Autores Puertorriqueños, 1942.

Brindis de Salas, Virginia. Pregón de Marimorena. Montevideo: 1946.

Castro, Fidel. "La libertad del arte y la revolución". Estética y marxismo. 2 tomos. Adolfo Sánchez Vásquez, ed. México: Ediciones Era, 1980. 403-410.

Davis, David Brion. The Problem of Slavery in Western Culture. Ithaca, NY: Cornell University Press, 1966.

Depestre, René. "Problemas de la identidad del hombre negro en las literaturas antillanas". Casa de las Américas 53 (1969): 19-28.

Fra Molinero, Baltasar. La imagen de los negros en la literatura española de los siglos XVI y XVII. Disertación de Ph.D., Indiana University, 1990.

Freyre, Gilberto. Casa grande e senzala: Formacão da familia brasileira sob o regime da economia patriarcal. Rio de Janeiro: Schmidt, 3a ed., 1938.

Fuller, Hoyt. "Towards a Black Aesthetic". The Black Aesthetic. Addison Gayle, Jr., ed. Nueva York: Doubleday and Company, Inc., 1971. 3-11. 
et. al., (ed.). The Norton Anthology of African American Literature. Nueva York: W.W. Norton \& Company, 1997.

Freud, Sigmund. "Jokes and the Comic". Comedy: Meaning and Form. Robert W. Corrigan, ed. Scranton, PA: Chandler Publishing Company, 1965. 253-262.

Gates, Henry Louis, Jr. Ed. 'Editor's Introduction: Writing 'Race' and the Difference it Makes". "Race," Writing, and Difference. Chicago: The University of Chicago Press, 1985. 1-20.

González-Pérez, Armando (Ed. y prólogo). Antología clave de la poesía afroamericana. Madrid: Alcalá, 1976.

Gubar, Susan. Racechanges: White Skin, Black Face in American Culture. Nueva York: Oxford University Press, 1997.

Guillén, Nicolás. Nicolás Guillén: Obra Poética 1920-1972. 2 tomos. La Habana: Editorial Arte y Literatura, 1974.

Guirao, Ramón (ed.). Orbita de la poesía afrocubana, 1928-1937: (Antología). La Habana: Ucar, García y Cía, 1938.

Hall, Stuart. "Culture, the Media and the "Ideological Effect"”. Mass Communication and Society. James Curran, Michael Gurevitch and Janet Woolacott, eds. Londres: Edward Arnold Ltd., 1977. 315-348.

"Race: The Floating Signifier". Director, Sut Jhaly. The Media Education Foundation, 1996.

Helg, Aline. Our Rightful Stare: The Afro-Cuban Struggle for Equality, 1886-1912. Chapel Hill: The University of North Carolina Press, 1995.

Herrera, Georgina. Grande es el tiempo. La Habana: Ediciones Unión, 1989.

Howe, Linda. "Nancy Morejón's "Negrismo" in the Revolutionary Era: The Question of Gender and Race in Cuba". Explicación de textos literarios 1-2/24 (1995-96): 91111.

Jackson, Richard. The Black Image in Latin American Literature. Albuquerque: University of New Mexico Press, 1976.

The Afro-Spanish American Author II: The 1980s: An Annotated Bibliography of Recent Criticism. West Cornwall, CT: Locust Hill Press, 1989.

Black Writers and the Hispanic Canon. Nueva York: Twayne Publishers, 1997.

James, Conrad. "Patterns of Resistance in Afro-Cuban Women's Writing: Nancy Morejón's "Amo a mi amo"". Framing the Word: Gender and Genre in Caribbean Women's Writing. Londres: Whiling and Birch, 1996. 159-168.

Jiménez, Blas. "El escritor afro-hispano y el proceso creativo". Afro-Hispanic Review 14/ 1 (1995): 3-9.

Johnson, Lemuel. The Devil, the Gargoyle, and the Buffoon: The Negro as Metaphor in Western Literature. Nueva York: Kennikat Press, 1971.

Konetzke, Richard (ed.). Colección de documentos para la historia de la formación social de hispanoamérica 5 tomos. Madrid: Consejo Superior de Investigaciones Superiores, 1953-1962.

Kubayanda, Josephat. The Poet's Africa: Africanness in the Poetry of Nicolás Guillén and Aimé Césaire. Nueva York: Greenwood Press, 1990. 
Kutzinski, Vera. "Afro-Hispanic American Literature". The Cambridge History of Latin American Literature II. 3 tomos. Roberto González Echevarría y Enrique PupoWalker, eds. Cambridge: Cambridge University Press, 1996. 164-194

López-Baralt, Mercedes. "Preludio en Boricua o la ironía como programa poético en el Tuntún palesiano". Revista de estudios hispánicos 17-18 (1990): 329-338.

Luis, William. "Race, Poetry, and Revolution in the Works of Nancy Morejón". Hispanic Journal 14/2 (1993): 83-103.

Mansour, Mónica. "Circunstancia e imágenes de la poesía negrista”. Revista de la Universidad de México 25/12 (1970): 25-32.

(introducción) y José Luis González (eds.). Poesía negra de América. México: Ediciones Era, S.A., 1976.

Martin Alcoff, Linda. "The Problem of Speaking for Others". Who Can Speak: Authority and Critical Identity. Judith Roof and Robyn Weigman, eds. Urbana: University of Illinois Press, 1995. 97-119.

Marzán, Julio. "The Poetry and Antipoetry of Luis Palés Matos". Callaloo 18/2 (1995): 506-523.

Moore, Robin. "Representations of Afrocuban Expressive Culture in the Writings of Fernando Ortiz". Latin American Music Review 15/1 (1994): 32-54.

Nationalizing Blackness: Afrocubanism and Artistic Revolution in Havana, 19201940. Pittsburgh: Pittsburgh University Press, 1997.

Morejón, Nancy. "El concepto de nacionalidad en Nicolás Guillén". Casa de las Américas 128 (1981): 26-42.

“Transculturación y mestizaje en Nicolás Guillén”. Casa de las Américas 132 (1982): 63-86.

Mullen, Edward. "'Los negros brujos': A Reexamination of the Text". Cuban Studies 17 (1987): 111-132.

Afro-Cuban Literature: Critical Junctures. Westport, CT: Greenport Press, 1998.

Onís, Federico de. (ed.). "Introducción" a Luis Palés Matos: Poesía (1915-1956). Barcelona: Editorial Universitaria Universidad de Puerto Rico. 7-28.

Ortiz, Fernando. "La poesía mulata: Presentación de Eusebia Cosme". Revista Bimestre Cubana 34 (1935): 205-213.

"Los últimos versos mulatos". Revista Bimestre Cubana 35 (1935): 321-336.

"Más acerca de la poesía mulata: Escorzos para su estudio". Revista Bimestre Cubana 37 (1936): 23-39, 218-237.

"Informe del doctor Fernando Ortiz, Presidente de la Sociedad de Estudios Afrocubanos, aprobado por la Junta Directiva de dicha Sociedad, pronunciándose en favor del resurgimiento de las comparsas populares habaneras". Las comparsas populares del carnaval habanero, cuestión resuelta. Ed. y prefacio de Antonio Beruff Mendieta. La Habana: Molina y CíA., 1937. 9-20. .

Hampa afrocubana: los negros brujos (apuntes para un estudio de etnología criminal.) [1906]. Prólogo de Alberto N. Pamies. La Habana: Editorial de Ciencias Sociales, 1975.

Palés Matos, Luis. Tuntún de pasa y grifería. Ed. y prólogo de Jaime Benítez. San Juan de Puerto Rico: Biblioteca de Autores Puertorriqueños, 1974. 
Pieterse, Jan Nederveen. White on Black: Images of Africa and Blacks in Western Popular Culture. New Haven: Yale University Press, 1992.

Ruiz del Vizo, Hortensia. Black Poetry of the Americas: A Bilingual Anthology. Miami: Ediciones Universal, 1972.

Tannenbaum, Frank. Slave and Citizen: The Negro in the Americas. Nueva York: A.A.Knopf, 1942.

Thomas, Ena. "Black Images in the Poetry of Palés Matos". Afro-Hispanic Review 9/1-3 (1990): 30-33.

Valdés-Cruz, Rosa. La poesía negroide en América. Nueva York: Las Américas Publishing Company, 1970.

Weedon, Christopher. Cultural Politics: Class, Gender, Race and the Postmodern World. Oxford: Blackwell, 1995.

Zenón-Cruz, Isabelo. Narciso descubre su trasero: El negro en la cultura puertorriqueña. 2 tomos. Humacao, PR: Editorial Furidi, 1975. 